\section{Homologies of the Genital Ducts of Insects.}

IT is unfortunate that even the most recent textbooks of entomology are not up-to-date in their accounts of the above organs. It is only with regard to the ectodermal parts of the ducts that opinions have differed; otherwise it is admitted by all that ovaries and oviducts correspond to the testes and vasa deferentia respectively. In every book, old or new, one finds the median ejaculatory duct homologised with the median vagina. This homology is open to serious objection : the ejaculatory duct opens in all insects, excepting the Ephemeroptera, behind the ninth sternite, and is unpaired from the very beginning, while the vagina or the uterus opens in

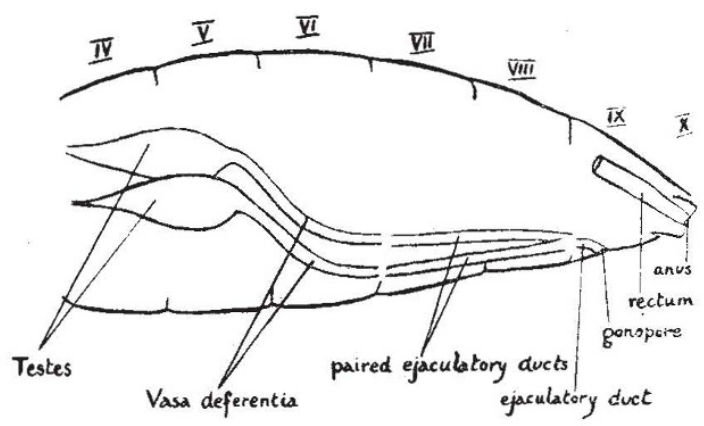

Male

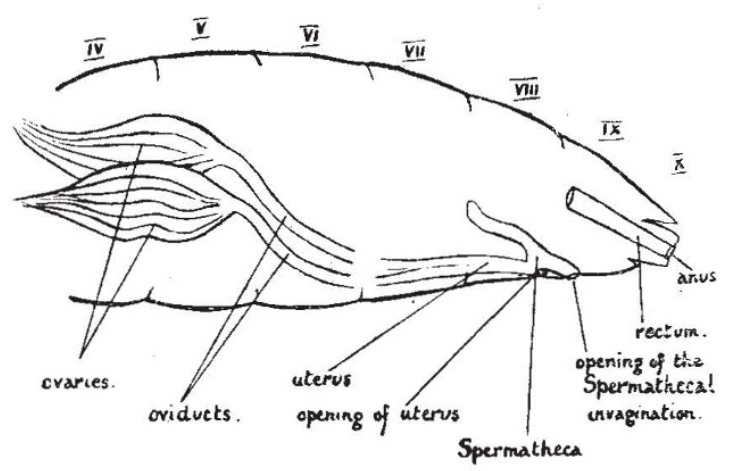

Female

Fig. r. - Scheme of the development of the reproductive organs of an insect. Accessory gland not shown.

most insects between the eighth and ninth sterna, and is paired in origin in many orders.

In the young male there is an hypodermal invagination of the body wall behind the ninth sternum, the rudiment of the median ejaculatory duct. This invagination at its anterior end, about the posterior region of the eighth sternum, meets and opens into a pair of ectodermal ducts, termed the paired ejaculatory ducts, which as development proceeds get into communication with the vasa deferentia. In the case of the young female there is also an invagination of the integument behind the ninth sternite which develops into the spermatheca. The spermathecal rudiment about the posterior margin of the eighth sternum opens into an ectodermal duct, the uterus or vagina, which, as mentioned above, arises in many insects by coalescence of a pair of ducts. The uterus at a later stage in development becomes continuous with the oviducts. Evidently, therefore, the median ejaculatory duct of the male corresponds to the spermatheca of the female, and not to the vagina or uterus. The homologue of the latter are the paired ejaculatory ducts. Diagrams of the scheme of the organs appended herewith illustrate the above remarks (Fig. I).

The only difference (but which has caused a considerable amount of confusion) between the organs of the two sexes is that while the median ejaculatory duct meets and opens into the paired ejaculatory ducts at its extreme anterior end, the spermatheca does so about the middle of its length, with the consequence that its anterior half remains free, increases in size, and appears as a diverticulum of the uterus. Moreover, unlike the uterus, the paired ejaculatory ducts have no opening of their own in the present-day insects. But in Coleoptera, and probably in Diptera also, the uterus, like the latter, has, morphologically speaking, no opening of its own and communicates with the exterior through the opening of the spermatheca, and therefore the female gonopore, unlike that in other orders, lies behind the ninth sternum. The spermatheca, except in the Coleoptera, Diptera, etc., loses its proper opening and communicates with the exterior by the opening of the uterus. In the Lepidoptera, however, both the spermatheca and the uterus retain their proper apertures even in the adult stage, with the consequence that there are two " genital openings," one behind the other, in this order. In the Ephemeroptera also there are two openings, but they lie on the same segment, the seventh.

\section{Zoological Laboratory, \\ Cambridge, April 22.}

\section{Fossils and Leonardo da Vinci.}

In his valuable and sympathetic appreciation of Huxley on the occasion of the centenary celebrations on May 4, Prof. Poulton incidentally referred to the puzzled discussions of naturalists of former days concerning the fossil sharks' teeth ("glossopetræ") that were found in Italy.

It is interesting to compare their mental attitude and their almost complete and unimaginative ignorance with the acute and unerring perception of the supreme genius of all time-Leonardo da Vinci.

In "The Literary Works of Leonardo da Vinci" (Richter, I 883, p. 208 et seq.) he discusses very fully the presence of fossils in the Italian mountains. His immediate object is to show that the Noachian flood could not be responsible for this; and his many-sided arguments indicates the clearest understanding of the formation of strata by deposition from rivers, and of earth movements, in their connexion with the preservation and present position of fossils. His particular views are supported by the following statement:

"And if you were to say that these shells were created, and were being continually created in such places by the nature of the spot, and of the heavens which might have some influence there, such an opinion cannot exist in a brain of much reason ; because here are the years of their growth, numbered on their shells, and there are large and small ones to be seen which could not have grown without food, and could not have fed without motion-and here they could not move." With such a mental attitude (existing at a period that was steeped in astrology) what a mighty ally Leonardo would have been to Darwin and Huxley!

One of his other arguments against the assistance of the Deluge, in the part of Italy that he investigated, is characteristic of his incessant interest and scientific watchfulness. "We have it in the Bible that this NO. 2898 , VOL. I I 5$]$ 